\title{
PROFESSOR(A): A PROFISSÃO QUE PODE MUDAR UM PAÍS? ${ }^{1}$
}

\author{
Olinda Evangelista ${ }^{2}$ \\ JocemaraTriches $^{3}$
}

\begin{abstract}
RESUMO
Este artigo resulta de pesquisas em andamento que tratam das atuais políticas de formação docente para a Educação Básica no país. Procuramos demonstrar, mediante análise de documentos do Estado e de Organizações Multilaterais ou de seus intelectuais, o ideário disseminado e como tem sido construído o consenso em torno da responsabilização do professor pelo futuro do Brasil, traduzido como desenvolvimento econômico e social no horizonte capitalista. Tal intento compõe um conjunto de políticas educacionais consolidadas a partir da década de 1990, articuladas à reestruturação produtiva tendo em vista capturar a subjetividade e o exercício profissional do professor. O slogan "Seja um professor!", construído pelo Estado, integra um discurso emblemático e ideológico. Duas de suas faces são examinadas: de um lado, enaltece o docente e o responsabiliza pela ascensão social dos alunos e, de outro, articula seu desprestígio via discursos denegridores e sua desqualificação por meio de programas formativos aligeirados e pragmáticos. Concluímos que a demanda oficial é irrealizável, posto que os problemas nacionais não se originam na esfera de atuação do professor, muito menos sua solução.

Palavras- chave: Política educacional - 1990-2014; Formação docente; Organizações Multilaterais.
\end{abstract}

\section{TEACHERS: CAN THEY CHANGE A COUNTRY?}

\section{ABSTRACT}

This article stems from an ongoing research inquiry into the current teacher training policies for basic education in Brazil. By assessing documents from the Brazilian government and multilateral agencies, as well as widely disseminate ideas on the topic, we show how a broad consensus has been built up on holding teachers accountable for the future of Brazil, as a guide to foster economic and social development. Such attempt comprises a set of education policies consolidated as of the 1990s that is intimately linked to the productive restructuring in order to affect the teacher's professional subjectivity and practice. "Be a teacher!" became therefore the state motto as part of a symbolic and ideological discourse. Two aspects of this process are hereby examined: first, the motto praises the teachers and holds them responsible for the student's social mobility; second, it articulates the teachers' prestige via disparaging speeches and disqualification through streamlined and pragmatic training programs. We conclude that the official demand is unrealistic, given that no national problem - much less what should be done about itemerges from the teacher's areas of activity.

Key words: Education policy (1990-2014); Teacher training; Multilateral agencies. 


\section{INTRODUÇÃO}

[...] os lugares-comuns, as frases feitas, os bordões, os narizes-de-cera, as sentenças de almanaque, os rifões e provérbios, tudo pode aparecer como novidade; a questão está só em saber manejar adequadamente as palavras que estejam antes e depois [...]. (SARAMAGO, 2003)

O slogan ${ }^{4}$ que serve de título a este capítulo está registrado no website "Seja um professor" (BRASIL, 2013e) $)^{5}$, do Ministério da Educação (MEC). A convocação é desafiadora: "venha construir um Brasil mais desenvolvido, mais justo, com oportunidades para todos! Seja um professor!"; "Muitas pessoas já escolheram mudar o Brasil. Conheça as histórias de quem faz o nosso país melhor"; "A Profissão que pode mudar um país" (BRASIL, 2013e). A convocatória obscurece as intenções abissais presentes na produção de bordões e brocardos, seja em termos de Educação, da escola ou da formação docente.

Sua aparente singeleza quer convencer-nos de que o desenvolvimento econômico do país supõe e impõe a adesão do professor ao projeto histórico burguês contemporâneo. Temos em vista, precisamente, evidenciar as "palavras que [estão] antes e depois" deste slogan, que fazem parte das reformas educacionais iniciadas desde os anos de 1990, no Brasil, e intensificadas na última década. Tais reformas se articulam com base em interesses comuns, com proposições de Organizações Multilaterais (OM) que têm se destacado na coordenação e formulação de um conjunto de políticas educacionais para o mundo. Nosso esforço foi o de demonstrar o ideário que vem sendo disseminado, no Brasil, em torno do papel do professor, incensado à exaustão. Tal procedimento se deve à função de "gerar e transmitir um quadro de valores que legitima os interesses dominantes". (MÉSZÁROS, 2005, p. 35).

O cinismo da formulação se assenta sobre o que afirmou o ministro da Educação, Aloizio Mercadante, ser um problema: o Brasil sofre de falta de "eficiência" em tecnologia e inovação. A solução, como soe acontecer nos projetos governamentais, para "aumentá-la a médio e longo prazo é a educação. Ou nós formamos pra valer os nossos jovens, ou nós não teremos competitividade naquilo que importa, que são os setores exportadores de futuro", neste caso, é preciso investir na minimização das "deficiências do país no desenvolvimento de tecnologias e na inovação no ramo da produção". (SANTOS, 2012).

Não se pode perder de vista que a área educacional é lócus de intenso litígio entre interesses de classes. Mészáros (2005, p. 48) demonstra que essa contenda envolve posicionamentos antagônicos que estão na base do sentido da educação. De um lado, encontra-se uma perspectiva cuidadosamente elaborada que desloca a origem dos problemas socioeconômicos da relação capital-trabalho para seus efeitos aparentes e imputa à educação a tarefa de solucioná-los. De outro lado, para o autor, "apenas a mais ampla das concepções de educação nos pode ajudar a perseguir o objetivo de uma mudança verdadeiramente radical, proporcionando instrumentos de pressão que rompam a lógica mistificadora do capital.”. Robertson (2012, p. 299) sintetiza essa dupla possibilidade ao afirmar que a educação

[...] é mais do que um direito humano, ou simplesmente um sistema pelo qual o conhecimento oficial é transmitido e adquirido. É também mais do que um bem público. É um espaço altamente disputado, de condição pública e potencialmente emancipatória, importante para o nosso futuro, mas cujo próprio poder de decisão acerca desses valores é questionado. 
Não surpreende, por conseguinte, que a classe dominante lance mão das alianças possíveis para alcançar seus intentos, nem que a Educação seja a escolhida para compor a essência de suas explicações para os problemas socioeconômicos. Tal racionalização, reconstruída pelo neoliberalismo, após os anos de 1990, no Brasil, insiste em que a falta de educação formal ou uma de má qualidade produz o atraso nacional, perspectiva própria da Teoria do Capital Humano. O oposto disso resultaria no desenvolvimento tecnológico e na inovação da produção para os quais o empresariado é considerado excelente parceiro.

Os lemas evidenciam o quão é conturbado o âmbito das disputas em torno da educação institucionalizada e, nela, da profissão docente. Podemos afirmar que está em disputa a capacidade de pensar, de refletir, de discernir do professor - e, por consequência, a de seus alunos, filhos de trabalhadores e trabalhadores que frequentam a escola pública.

Neste artigo, demonstramos como é construído o consenso em torno da responsabilização ${ }^{6}$ do professor pelo futuro do Brasil, traduzido como "desenvolvimento nacional". Os exemplos oferecidos de slogans- formulados de diferentes maneiras evidenciam o processo de desqualificação da formação docente com a subsequente proposta de sua reconversão, ou seja, sua formação em novos termos. Esta dualidade na abordagem da escola e da docência - responsáveis pela criação e, simultaneamente, pela solução dos problemas socioeconômicos - é difundida pela mídia, por organizações não governamentais (ONG), por organizações empresariais, pelo aparelho de Estado, por OM, entre outras instituições. Interessou-nos analisar mais detidamente os bordões produzidos pelo aparelho de Estado e por OM, evidentemente articulados com os mencionados.

Entendemos que essas organizações compõem organicamente a lógica do capital, posto que expressam um projeto para o qual se busca a adesão, condição sinequa non para a coesão que possibilite uma ação social alienadora. Da ótica de Fontes (2010, p. 348), trata-se de um projeto pedagógico que "sob direção empresarial, procura reconfigurar a classe trabalhadora e a própria sensibilidade social nacional para as novas condições psicofísicas da divisão internacional do trabalho, nas quais o Brasil passa a atuar como 'parceiro' do capital-imperialismo". Ademais, o sentido último desse projeto não pode ser apreendido no âmbito da política educacional do Estado.

É necessário explodir seus limites para compreendermos que não se trata apenas da formação - adequada ou inadequada - do professor, mas das determinações históricas para reposição da hegemonia burguesa definida em termos neoliberais, de um modelo econômico que tem no privilegiamento do setor financeiro e nas políticas assistenciais de massa seus objetivos centrais.

\section{O DISCURSO DAS ORGANIZAÇÕES MULTILATERAIS}

Como referido, a década de 1990, no Brasil, produziu um modelo político de corte neoliberal, no qual OM têm atuado mundialmente na proposição e realização de um projeto tanto econômico quanto educacional. Neste cenário, a posição do Brasil, como país periférico, é subordinada, embora ativa e concordante com as orientações do grande capital internacional. Partindo desta compreensão, Neves e Pronko (2008, p. 8) assinalam que

O capitalismo dependente constitui-se, então, em uma forma específica de desenvolvimento capitalista em que as burguesias locais são sócias menores e subordinadas às burguesias dos centros hegemônicos do capitalismo, e se caracteriza pela hipertrofia de um desenvolvimento desigual e combinado que concentra riqueza e miséria, superexploraçãoda 
classe trabalhadora e a dominância de processos educativos e formativos para o trabalho simples na divisão internacional do trabalho.

Partilhando interesses burgueses com diversos países, as OM, via diferentes táticas, estabelecem metas, definem setores prioritários e estratégicos e organizam a execução de sua agenda em médio e longo prazo (OEI, 2003a; UNESCO; CONSED, 2007; BANCO MUNDIAL, [2011?]). Entretanto, o projeto internacional capitalista é diferentemente apropriado segundo as conjunturas locais. Conforme demonstrado por Triches (2010), os elementos que comprovam este consenso podem ser encontrados em documentos de OM ou em trabalhos publicados por seus intelectuais que, muitas vezes, estão vinculados ao aparelho estatal de diferentes países, empresas, organizações não governamentais, instituições de ensino, fundações, entre outros espaços.

O consenso que se busca construir ou consolidar é o de que a pobreza se origina na falta de escolarização de boa qualidade e a solução para esse problema encontrar-se-ia na própria escola. Entendemos por consenso, de acordo com Gramsci (1989, p.18), as "características difusas e dispersas de um pensamento genérico de uma certa época em um certo ambiente popular”. Para Gramsci (1989, p. 11), ele se efetiva pela adesão

[...] 'espontâne[a]' dad[a] pelas grandes massas da população à orientação impressa pelo grupo fundamental dominante à vida social, consenso que nasce 'historicamente' do prestígio (e, portanto, confiança) que o grupo dominante obtém, por causa de sua posição e de sua função no mundo da produção.

A adesão ao ideário capitalista pode ser consciente e voluntária ou inconsciente ${ }^{7}$. Neste processo, o intelectual é fundamental para que uma concepção de mundo, própria de uma classe, torne-se hegemônica. O intelectual orgânico ordena a visão de mundo de uma classe em detrimento dos interesses de outra classe (GRAMSCI, 1989). A hegemonia obtida pelos interesses burgueses em relação ao seu projeto educacional está ligada às ações pretensamente "humanizadoras" do capitalismo. "As mudanças sob tais limitações, apriorísticas e prejulgadas, são admissíveis apenas com o único e legítimo objetivo de corrigir algum detalhe defeituoso da ordem estabelecida, de forma que sejam mantidas intactas as determinações estruturais fundamentais da sociedade" (MÉSZÁROS, 2005, p. 25).

Organizações multilaterais têm comemorado nos últimos anos o consenso estabelecido no Brasil e na América Latina, afirmando que se observan una serie de características compartidas en las reformas curriculares de los países de América Latina que [...]dan cuenta de la aplicación de la mayoría de los principios y estrategias planteados en esta etapa [...](UNESCO, 2000, p. 67; 121) e que háum grande empeño puesto en que los docentes se "perfeccionen", "reconviertan", “actualicen" (OEI, 2003b, p. 1). Por sua vez, o Banco Mundial (BM) (2010), em documento sobre a agenda para os professores brasileiros, considera haver no país um compromisso amplo e positivo para melhorar a educação nacional, mencionando explicitamente o Compromisso Todos Pela Educação e o crescente número de grupos industriais que estão investindo em escolas.

Falleiros, Pronko e Oliveira (2010, p. 51-52) afirmam que o BM, a partir dos anos 1960, foi uma "agência fulcral no âmbito do desenvolvimento", pois canalizou recursos dos países ricos para a África e a América Latina investindo em projetos de combate à pobreza e à injustiça social. O BM tinha ainda outras duas funções: "importante papel educador para os governos periféricos" e "formar intelectuais capazes de disseminar tais 
ideias [...]. Tratava-se de modelar uma determinada visão de Estado e de gestão pública", fortalecendo o sentimento aparente de paz, consentimento e harmonia. Essa foi também estratégia de outras OM (TRICHES, 2010).

Verdugo (1996, p.70), em artigo publicado no Boletim do Projeto Regional de Educação para a América Latina e Caribe (PRELAC), ligado à UNESCO, afirma que a educação e a escola deben responder a losdesafíosdelnuevo contexto económico internacional. Complementa essa posição o pensamento da ex-presidenta do Programa de Promoção da Reforma Educativa na América Latina e Caribe (PREAL) no Brasil, Helena Bomeny (BOMENY, 2000, p. 17), ao argumentar que a educação é "o principal instrumento para o crescimento da economia, aumento de produtividade, além de propiciar a superação ou ao menos a diminuição do abismo interno da pobreza e o fosso externo que separa os países desenvolvidos daqueles em vias de desenvolvimento".

O Banco Mundial (1999, p. 5) comete o disparate de dizer que "existe uma estreita articulação entre a natureza da formação e da carreira docente e a estrutura econômica e social do país". Para a agência (BM, 2008, p. 28),

O Brasil não pode mais ignorar a economia do conhecimento - e isto não está ocorrendo. Um constante diálogo nacional discute reformas para apoiar o forte desempenho macroeconômico [...] e adequar os sistemas educacionais ineficientes e desiguais, que não estão produzindo o tipo de capital humano necessário à competitividade global de hoje.

A mesma analogia é feita em documento da Organização das Nações Unidas para a Educação, a Ciência e a Cultura (UNESCO) com o Conselho Nacional de Secretários de Educação (CONSED) (UNESCO; CONSED, 2007, p. 11) que considera que "as iniquidades em educação reproduzem em grande medida as desigualdades socioeconômicas, étnico-raciais e espaciais (urbano/rural) que caracterizam as sociedades da região". Em outro documento da mesma organização (UNESCO, 2007, p. 8), lê-se que es preciso reflexionar sobre cómo la educación puede contribuir al crecimiento económico, reducir las desigualdades, promover la movilidad social y ayudar a convivir en la diversidad $[\ldots]$.

Os excertos exibem a preocupação com as implicações da educação sobre a economia. A relação estabelecida entre ambas é de "mão única", isto é, imputa-se à educação a responsabilidade pelo desenvolvimento econômico da sociedade e pela superação da desigualdade, bem como ao indivíduo por suas precárias condições de reprodução da vida. Shiroma, Campos e Garcia (2005) chamam a atenção para estratégias discursivas presentes em documentos de política educacional, como esta da convocação do professor, para atuar no desenvolvimento econômico. Assinalam que as práticas empresariais são consideradas modelo a ser seguido:

Paulatinamente, os problemas educacionais vão sendo traduzidos como problemas de gestão da educação, de má administração. Somam-se à "lista das palavras mais usadas" vocábulos como monitoramento, gerenciar, avaliar, caracterizando a "linguagem da implementação" das medidas recomendadas. (SHIROMA; CAMPOS; GARCIA, 2005, p. 11)

Propaga-se a ladainha de que por meio da educação o sujeito ascenderá socialmente. Shiroma e Evangelista (2003, p. 3), ao analisarem a década de 1990, afirmavam que este tipo de discurso representava o artifício de "construir tanto a noção de 
crise educacional quanto a de sua autossolução. Ou seja, uma educação que se redimiria a si própria". Um ano mais tarde, as autoras assinalaram que "o que parece estar em causa é precisamente a gestão da crise social pela construção do professor e da escola como 'gerentes' dessa mesma crise, [...] destinada a construir a desejada aparência de 'poder do professor"”. (SHIROMA; EVANGELISTA, 2004, p. 527).

Esse debate emrelaçãoaosprofessores está posto no âmbito da reforma educacional desde meados da década de 1990. Lella (1999, p. 1), na ocasião consultor da Organização dos Estados Ibero-americanos (OEI), assinalava que constituía una condición de posibilidad nodal de tales reformas la participación activa y creativa del personal docente, con actitudes y competencias específicas. Desse ponto de vista, os professoressão vistos como campo de tensão, poisel tema de los docentes sobresale como uno de los más críticos y un tema pendiente en todos los países de la región. (UNESCO, 2000, p. 134).

Por sua vez, Torres (2001, p. 22) conclamavaorganizaciones docentes, universidades, ONGs, empresa privada, iglesias, ciudadanía en general para secoresponsabilizarem pela formação docente. Vaillant $(2004$, p. 6), consultora de várias OM, concorda comessa perspectiva: [...] es uno de los problemas más difíciles enfrentados por los gobiernos y las sociedades por sus implicancias políticas, ideológicas y financieras. Posteriormente, afirmou que "transformar a educação e reinventar o modelo de docência são tarefas sociais, coletivas, que envolvem o Estado, os professores e toda a sociedade". (VAILLANT, 2005, p. 51).Alémdisso, o RelatórioMcKinsey (2008, p. 10)refere, na Lição 1 , que "a qualidade de um sistema educacional está diretamente relacionada à qualidade dos professores" 8 .

O discurso que responsabiliza os docentes pela solução de problemas relativos à pobreza, sob o signo do empoderamento, expõe a desqualificação operada contra ele. Resulta disso o descrédito da formação e do profissional atual, indicado como ultrapassado e fracassado frente às demandas do prometido e inevitável "novo" mundo. Evangelista (2001), referindo-se às políticas e às diretrizes de formação de professores da década de 1990, denunciou essa estratégia discursiva: professor "novo" versus professor "tradicional”. Segundo ela, o que está posto pelas políticas é que

[...] se há um "novo" professor, há um 'tradicional' a ser descartado: restrito à sala de aula; prescritivo; não investigador; distanciado da prática; sem domínio das tecnologias; sem capacidade de gerir e atribuir sentido ao conhecimento; desqualificado para atender as diferenças de sua clientela - crianças, jovens e adultos; crente no voluntariado. A essa contrapõe-se o desejado, "novo" e "profissional". (EVANGELISTA, 2001, p. 15).

Para propagar essas ideias, alguns eventos foram realizados no Brasil sobre a profissão docente, especialmente a partir dos anos 2000, promovidos por OM, destacandose a Conferência Regional "O desempenho dos professores na América Latina e no Caribe: novas prioridades” (REGO; MELO, 2002);o Seminário Internacional sobre Políticas de Profissionalização Docente (UNESCO; CONSED, 2007); o 1. ${ }^{\circ}$ Seminário Internacional dos Grupos de Pesquisa da Cátedra UNESCO sobre Profissionalização Docente(FCC, 2011) ${ }^{9}$ e o Congresso Internacional "Educação: uma Agenda Urgente" (TPE, 2011). Além de eventos, algumas pesquisas sobre o perfil e formação dos professores foram publicadas nos últimos anos por OM ou por empresas e instituições nacionais a elas vinculadas, como os livros Professores são importantes: atraindo, desenvolvendo e retendo professores eficazes (OCDE, 2006) e Professores do Brasil: impasses e desafios (UNESCO; GATTI; 
BARRETO, 2009). Publicou-se ainda o relatório Atratividade da carreira docente no Brasil - relatório preliminar (FCC, 2009). No final de 2012, a UNESCO lançou a iniciativa Educação em Primeiro Lugar, apoiada por Ban Ki-moon, Secretário-geral da Organização das Nações Unidas (ONU). Nas palavras do Secretário-geral, "quando colocamos a educação em primeiro lugar, nós podemos reduzir a pobreza e a fome, acabar com o desperdício de talentos em potencial e esperar por sociedades mais fortes e melhores para todos." (UNESCO, 2013).

A divulgação de slogans, como o que dá título a esse texto, induz, de imediato, a um desprestígio dos sujeitos que escolhem ou escolheram a profissão, da formação, da atuação e da carreira docente (OCDE, 2006). Divulga-se que as consequências dessa situação aparecem nos resultados das avaliações nacionais e internacional, como o Exame Nacional do Ensino Médio (Enem), o Programa Internacional de Avaliação de Alunos (Pisa), entre outros.Mello (2005, p. 26) - consultora do Banco Interamericano de Desenvolvimento (BID) e do BM entre 1993-1996 e, atualmente, da UNESCO -, alegou que os docentes "são parte do problema por causa do despreparo, do corporativismo, da acomodação a uma carreira que expulsa os melhores". Vaillant (2005, p. 47) se excede ao afirmar que "a formação docente tem a honra de ser, simultaneamente, o pior problema e a melhor solução em educação".

No caso do BM, seu posicionamento sobre os docentes não sofreu alterações substantivas entre fim da década de 1990 e final da década de 2000: em 1999, afirmavam que "as raízes do problema [estavam] na formação dos docentes, tanto em sua etapa inicial como durante toda a sua carreira profissional [...]" (BANCO MUNDIAL, 1999, p. 5); em 2008, seus intelectuais acusavam a formação dos professores de treiná-los "na filosofia em vez de na prática de ensino", centrada na memorização e repetição e por não haver "penalidades nem recompensas para o desempenho do professor e menos ainda para o aprendizado do aluno". (RODRIGUEZ; DAHLMAN; SALMI, 2008, p. 39; 185).

As reformas educacionais deflagradas ao longo das duas últimas décadas e suas sucessivas alterações foram analisadas por Neves e Martins (2010, p. 37) que alertam para o fato de que estamos vivenciando uma tentativa de "reeducação escolar e política", denominada "repolitização da política" que induz a uma redução dos

níveis de consciência política coletiva das várias frações da classe trabalhadora, impulsiona seus intelectuais coletivos a pautarem suas agendas políticas por demandas que, embora realizem mudanças parciais nas condições de trabalho e de vida das classes dominadas, mantêm praticamente inalteradas as relações de exploração e de expropriação concernentes às relações sociais capitalistas.

Mészáros (2005, p. 62) esclarece que

as 'reformas', na prática são estruturalmente irrealizáveis dentro da estrutura estabelecida de sociedade. [...] Pois os defeitos específicos do capitalismo não podem sequer ser observados superficialmente, quanto mais ser realmente resolvidos sem que se faça referência ao sistema como um todo, que necessariamente os produz e constantemente os reproduz.

Na avaliação do BM (2010a, p. 2), o Ministério da Educação (MEC) do Brasil se destaca por sua "forte função normativa" que tem levado a "novos padrões para professores, programas de formação profissional de professores de mais alta qualidade, e 
seleção de livros escolares". Quanto aos padrões ideais de docentes, é desejável: que seja líder, "investigador" e colaborador na gestão escolar; que trabalhe com a diversidade na perspectiva da "escola inclusiva"; que tenha conhecimento e explore conteúdos artísticos, corporais, valores éticos, afetivos e morais; que se disponha a aceitar o desafio de um novo papel; seja reflexivo, flexível, comprometido com as mudanças, protagonista, crítico de sua prática, autônomo, criativo, solucionador de problemas, comprometido com a comunidade, mobilizador de recursos, que tenha preocupação com as questões ambientais, que saiba trabalhar eficazmente em equipe e que tenha capacidade de aprender e lidar com novas habilidades (UNESCO; OEA; MERCOSUL, 2003; OEI, 2003a; UNESCO, 2006; UNESCO, 2007; UNESCO; CONSED, 2007; BM, 2010b). Comessas características e competências, o professor deve viabilizar um

aprendizado ativo que privilegia a flexibilidade do raciocínio, o raciocínio conceitual e a habilidade para solucionar problemas - em outras palavras, as mesmas características necessárias aos trabalhadores adultos para que possam competir em uma economia baseada em conhecimento. (RODRIGUEZ; DAHLMAN; SALMI, 2008, p. 39).

Em síntese, um dos objetivos de tais políticas é que os professores sejam reconvertidos e façam o mesmo com seus alunos, tendo no horizonte adaptá-los às demandas do setor produtivo. Este trabalhador facilitaria a efetivação da ampliação da mais-valia relativa que depende, necessariamente, da produtividade do trabalho que, por sua vez, envolve conhecimento e tecnologia, gestão do trabalho e qualificação da força de trabalho (MARX, 2012). De fato, há um vínculo entre educação e economia. Entretanto, não se pode perder de vista que nesta sociedade esta articulação é de mútua dependência, embora o campo econômico seja determinante em última instância. Para Neves (2004, p. 10),

Daí depreende-se que ela [educação] se configura em meio empregado pela classe dominante e dirigente no Brasil de hoje para que a classe trabalhadora pense minimamente e os que exercem funções intelectuais se tornem, em sua grande maioria, especialistas comreduzida capacidade de elaboração da crítica às relações sociais vigentes.

Os slogans em circulação no Brasil obscurecem essas determinações. O ideário que sustenta o projeto histórico subjacente se apoia num conjunto de elementos expressivos das relações capitalistas atuais de produção da existência. Entre eles, ressaltam as tecnologias de informação e comunicação, a microeletrônica, a ênfase sobre áreas específicas do conhecimento escolar, caso da Matemática e das Ciências, a extensa privatização da Educação e da Cultura; a implementação de programas para desenvolvimento do empreendedorismo. Como indicado por Leher $(2012$, p. 2), "a educação no capitalismo é unilateral, pois tem como pressuposto a divisão social do trabalho que opõe o trabalho intelectual ao trabalho simples (sem esquecer que estes são históricos, tendo seu conteúdo alterado pelo grau do desenvolvimento tecnológico da produção)".

$\mathrm{Na}$ sequência, veremos as estratégias usadas pelo Estado brasileiro nas últimas décadas para dar conta do primeiro desafio proposto pelo $\mathrm{BM}-\mathrm{e}$, conforme demonstrado, consensual entre outras organizações e intelectuais -, como uma questão em aberto, apesar das inúmeras ações empreendidas pelos governos. 


\section{O QUE O SLOGAN CRIADO PELO ESTADO ESCONDE}

A reforma educacional, empreendida a partir dos anos de 1990, respondeu às demandas de novos posicionamentos estatais - caso da reforma do Estado no governo FHC - e à reestruturação econômica capitalista. Segundo Neves e Pronko (2008, p. 25), a efetivação dessa reforma tem se dado com

[...] a ampliação quantitativa dos anos de escolaridade básica e uma organização curricular voltada mais imediatamente para o desenvolvimento de capacidades técnicas e de uma nova sociabilidade das massas trabalhadoras que contribuam para a reprodução ampliada do capital e para a obtenção do seu consentimento ativo para as relações de exploração e dominação burguesas na atualidade.

Para que esta nova sociabilidade e consentimento ativo das massas se efetivassem, outros âmbitos da educação foram contemplados com uma profusão de programas. Destacam-se as ações dirigidas aos professores, tendo em vista sua reconversão, que teve como uma de suas características a ampliação quantitativa de programas de formação (EVANGELISTA, 2009). A Lei de Diretrizes e Bases da Educação Nacional (LDBEN), Lei n. 9.394, de 20 de dezembro 1996 (BRASIL, 1996), expressa um dos movimentos mais importantes nessa direção, em consonância com a Declaração Mundial sobre Educação para Todos (DELORS, 2000). O Art. 62 da LDBEN, em sua formulação original, rezava que a formação de docentes para a Educação Básica se daria em nível superior, admitindose a formação mínima em nível médio, na modalidade Normal, para o magistério na Educação Infantil e séries iniciais do Ensino Fundamental. Complementava o $\S 4^{\circ}$, do Art. 87: no prazo de uma década os professores deveriam ter nível superior ou formação em serviço. Como se sabe,essa indicação não se realizou. $\mathrm{O} \S 2^{\circ}$ do artigo $3^{\circ}$ do Decreto n. 3.276, de 6 de dezembro de 1999 (BRASIL, 1999) definiu a referida formação "exclusivamente em cursos normais superiores", então criados. O movimento dos educadores derrubou essa indicação, mantendo-se a formação como atribuições da licenciatura em Pedagogia, do Curso Normal Superior e do Curso Normal em nível médio.

Mais de dez anos passados da LDBEN,o Decreton. 6.755, de 29 de janeiro de 2009, instituiu a Política Nacional de Formação de Profissionais do Magistério da Educação Básica (BRASIL, 2009), assumida como “compromisso público de Estado". Um dos objetivos dessa política foi o de "ampliar o número de docentes atuantes na educação básica pública que tenham sido licenciados em instituições públicas de ensino superior, preferencialmente, na modalidade presencial" (BRASIL, 2009, p. 2), evidenciando um recuo em relação à formação docente em nível superior, já que, nesse momento, deveria ter se dado na plenitude ${ }^{10}$. A Lei n. 12.796, de 4 de abril de 2013 (BRASIL, 2013d), alterou, entre outros, o Art. 62 da LDBEN,repondo a exigência de formação superior para a docência, mas mantevea formação mínima em nível médio, na modalidade normal.

O "compromisso público de Estado" com a formação docente foi motivo de pronunciamento, em 2008, de DilvoRistoff, então diretor da Educação Básica da Capes (BRASIL, 2008), eivado de uma crítica à Universidade pública como agência de formação. Afirmou durante a $60^{\mathrm{a}}$ Reunião da SBPC que existia "um apartheid" e falta de diálogo entre campi universitários e escolas básicas, entre professores do Ensino Superior e docentes da Educação Básica. Para ele, 
QUE SE FORMA É O QUÍMICO E NÃO O PROFESSOR DE QUÍMICA, O FÍSICO E NÃO O PROFESSOR DE FÍSICA, O BIÓLOGO E NÃO O PROFESSOR DE BIOLOGIA. ENQUANTO ESTE APARTHEID CONTINUAR, A FORMAÇÃO DO PROFESSOR CONTINUARÁ SENDO UM RÓTULO, UM TÍTULO SEM CONEXÃO COM AS DEMANDAS DA ESCOLA. (BRASIL, 2008)

A matéria, divulgada pelo portal do MEC, oferecia informações que atestariam o compromisso público de transformar essa realidade por meio do Programa de Apoio ao Plano de Reestruturação e Expansão das Universidades Federais (Reuni) (BRASIL, 2007), dos Institutos Federais de Educação, Ciência e Tecnologia (Ifet) (BRASIL, 2013c) e da Universidade Aberta do Brasil (UAB) (BRASIL, 2006b), exemplos de "investimentos expressivos que vão promover uma expansão significativa na formação de professores" (BRASIL, 2008). Para Ristoff, essas ações tinham em vista "pagar a dívida" com a Educação Básica "em 10 anos": "Quando [tivermos] pago esta dívida educacional, o Brasil estará pronto para assumir o seu papel entre os líderes mundiais nas artes, nas ciências e nas tecnologias de ponta". (BRASIL, 2008).

Aparentemente, o MEC tem dado centralidade aos professores e à sua formação no âmbito da regulamentação; contudo, isso não se constata nos números recentes publicados pelo próprio governo federal. Com base doResumo Técnico do Censo Escolar da Educação Básica de 2011e na Sinopse do Censo Escolar da Educação Básica de 2013 (BRASIL, 2012; 2013f), comparamos os números dos professores formados entre 2007, 2011 e 2013.

Quadro 1: Total de funções docentesna Educação Básica no Brasil, por titulação, 2007-2013

\begin{tabular}{|c|c|c|c|c|c|c|c|}
\hline \multirow{2}{*}{\multicolumn{2}{|c|}{ TOTAL DE PROFESSORES }} & \multicolumn{2}{|c|}{2007} & \multicolumn{2}{|c|}{2011} & \multicolumn{2}{|c|}{$2013^{11}$} \\
\hline & & \multicolumn{2}{|c|}{1.878 .284} & \multicolumn{2}{|c|}{2.039 .261} & \multicolumn{2}{|c|}{2.148 .023} \\
\hline \multicolumn{8}{|c|}{ Titulação (\%) } \\
\hline \multicolumn{2}{|c|}{ Ensino Fundamental incompleto } & \multicolumn{2}{|c|}{0.2} & \multicolumn{2}{|c|}{0.2} & \multicolumn{2}{|c|}{--} \\
\hline \multicolumn{2}{|c|}{ Ensino Fundamental completo } & \multicolumn{2}{|c|}{0.6} & \multicolumn{2}{|c|}{0.4} & \multicolumn{2}{|c|}{0.3} \\
\hline Ensino Médio & $\begin{array}{l}\text { Normal/ } \\
\text { Magistério }\end{array}$ & 30,8 & 25,3 & 25,4 & 19,0 & 11,0 & 14,0 \\
\hline \multicolumn{2}{|l|}{ Ensino Superior } & \multicolumn{2}{|c|}{68,4} & \multicolumn{2}{|c|}{74,0} & \multicolumn{2}{|c|}{74,7} \\
\hline
\end{tabular}

Fonte: Resumo Técnico do Censo Escolar da Educação Básica de 2011 (BRASIL, 2012) e Sinopse do Censo Escolar da Educação Básica de 2013 (BRASIL, 2013f).

Vemos um aumento na quantidade de professores da Educação Básica de pouco mais de $12,5 \%$ em seis anos. No que tange à formação em nível superior, o aumento foi de 6,6\%. No ano de 2011 ainda tínhamos professores que não concluíram o Ensino Fundamental - mais de 4.000 em 2011, mais que em $2007^{12}$. De outro lado, nem todos os professores com Ensino Médio o fizeram na modalidade Normal.

O Relatório permite compararmos o nível de atuação e a titulação. No ano de 2011, na Educação Infantil, 43,1\% dos professores não possuíam formação superior; nos anos iniciais do Ensino Fundamental 31,8\%; nos anos finais do Ensino Fundamental 15,8\% e no Ensino Médio 5,9\%. (BRASIL, 2012, p. 38). No ano de 2013, dos 6.438 professores que possuíam como titulação máxima o Ensino fundamental quase 50\% atuavam na Educação Infantil. Ademais, nesta etapa do ensino, $40 \%$ dos professores não possuíam formação superior; nos anos iniciais do Ensino Fundamental 29,24\%; nos anos finais do Ensino Fundamental 17,2\% e no Ensino Médio 7,04\% - desses, 204 docentes com Ensino Fundamental (BRASIL, 2013f). Ou seja, nas etapas iniciais da escolarização, menor é a 
titulação dos professores, ferindo a legislação em relação à formação mínima exigida. Os "380 mil profissionais que atuam no magistério da educação básica" matriculados na educação superior, significam para o MEC, que "está em curso um processo de melhoria da qualificação dos professores em exercício na educação básica" (BRASIL, 2012, p. 36). Tal afirmação requer certo cuidado, pois dos 380.669 professores da Educação Básica matriculados no Ensino Superior (ES), 204.044 estavam em cursos presenciais (54\%) e 176.625 na modalidade de Educação a Distância (EaD) (46\%). Desse mesmo total, $130.314(34 \%)$ estavam em instituições públicas, contra 250.355 em instituições privadas $(66 \%)$.

Outro dado que merece atenção se refere ao tipo de curso frequentado pelos professores: $83 \%$ estavam matriculados em cursos nas áreas de conhecimento da Educação Básica (Letras, Geografia, História, Física, Matemática etc.), porém os dados não permitem afirmar se em cursos de licenciatura ou bacharelado; os outros 17\% estavam matriculados em cursos fora da área da Educação - 10.926 em cursos de Direito $(9.484$ em instituições privadas); 7.429 em Administração (4.980 em IES privadas); 4.122 em Engenharia (2.116 em IES privadas); 3.611 em Psicologia (3.146 em privadas) e 30.253 em outros não identificados ${ }^{13}$ (desses, 16.504 matrículas em instituições privadas) (BRASIL, 2012). Havia, pois, grande quantidade de professores - 65.291 - em cursos não diretamente ligados à docência.

No caso dos cursos na área da Educação, o maior número de matrículas estava no de Pedagogia, 185.074 (49\% do total), seguido pelos cursos de Letras, 43.605 professores, Matemática, 18.487, e História, com 13.195 matrículas (BRASIL, 2012). Quanto ao curso de Pedagogia, do total de professores que exerciam a docência (185.074), 146.825 estavam matriculados em instituições privadas (79\%). Nessas instituições, $60 \%$ dos professores frequentavam a modalidade EaD. Com exceção da licenciatura em Pedagogia, nenhuma outra teve mais que 50\% de suas matrículas em EaD (BRASIL, 2012). Duas conclusões são óbvias: a predominância da formação em instituições privadas evidencia que a formação inicial é financiada pelos próprios professores, a exemplo da formação continuada; rompeu-se o compromisso de formação docente preferencialmente na forma presencial.

No caso da EaD, no Colóquio Formação dos Professores da Educação a Distância, realizado durante a Conferência Nacional de Educação (Conae), em 2010, o então Secretário da Educação a Distância do MEC, Carlos Eduardo Bielschowsky, afirmou estar "promovendo uma mudança significativa no quadro da educação brasileira, dando a esses professores uma oportunidade de formação" (BRASIL, 2010b). Em 2007 essa tendência foi claramente assumida por intelectuais do MEC, quando, no documento oficial Escassez de professores no Ensino Médio: propostas estruturais e emergenciais, publicado pelo MEC, lê-se: "Não dá para enfrentar a falta de professores no Ensino Médio sem colocar na agenda os novos meios de comunicação, principalmente devido ao grande déficit atual e às dimensões continentais do Brasil, mas é preciso verificar e garantir o sucesso e a eficiência desses métodos." (RUIZ; RAMOS;HINGEL, 2007, p. 22) ${ }^{14}$.

Ainda quanto aos dados, na Tabela 2, ampliamos a análise dos números de matrículas no Curso de Pedagogia no Brasil para além dos professores que atuam na Educação Básica e identificamos a mesma tendência.

Quadro 2: Matrículas em Cursos de Graduação em Pedagogia no Brasil, segundo natureza jurídica e modalidade, 2013 


\begin{tabular}{|c|c|c|c|c|c|}
\hline & \multirow{2}{*}{ Total } & \multicolumn{2}{|c|}{ NATUREZA JURÍDICA } & \multicolumn{2}{|c|}{ MODALIDADE } \\
\hline & & Público & Privado & Presencial & EaD \\
\hline \multirow[t]{3}{*}{ Total } & 614.835 & 138.741 & 476.094 & 319.571 & 295.264 \\
\hline & & & & Público = 106.429 & Público = 32.312 \\
\hline & & & & Privado $=213.142$ & Privado $=262.952$ \\
\hline
\end{tabular}

Fonte: BRASIL. Sinopse do Censo da Educação Superior, 2013 (BRASIL, 2015).

Os números indicam a lógica perversa das políticas de formação de professores. A formação é um nicho de mercado para instituições privadas, além de ser campo de consumo de toda espécie de materiais didáticos e de Tecnologias da Informação e Comunicação (TIC). A dívida do governo com os professores épaga sob a forma de políticas precárias, com repasse de responsabilidades para o setor privado, o que compromete o dinheiro público com o mercado do conhecimento. (NEVES; PRONKO, 2008). Reforça-se tal perspectiva quando o então Ministro da Educação, Fernando Haddad, afirmou em 2009 que o objetivo do Plano Nacional de Formação dos Professores da Educação Básica Sistema Nacional "é dar a todos os professores em exercício condições de obter um diploma específico na sua área de formação.” (BRASIL, 2009).

As evidências dessa política perversa não impedem o MEC de tentar criar a imagem da docência como profissão promissora, reconhecida socialmente. Recentemente, o Ministro afirmou, em frase lapidar dirigida ao Grupo de Líderes Empresariais (LIDE) ${ }^{15}$, que o "professor é o maior agente multiplicador de qualquer ação, ele é peça fundamental para a qualidade". Exortava o Lide à parceria com o governo tendo em vista arregimentar seu apoio à formação docente (PORTAL PLANETA UNIVERSITÁRIO, 2013). Para Freitas (2011, p. 5)

Os reformadores empresariais entendem que a escola é boa quando os alunos têm notas altas em português e matemática - no máximo incluindo ciências. Esta concepção de educação centra a ação da escola no desenvolvimento de um aspecto do ser humano - a habilidade cognitiva.

Da ótica de Mercadante, o encontro com o Lide "registrou recorde de perguntas e de presença, um ótimo indicador de interesse [...]". "Isso mostra que o Brasil realmente está debatendo a educação, que a educação realmente está na pauta." (PORTAL PLANETA UNIVERSITÁRIO, 2013) ${ }^{16}$. Entenda-se por Brasil os empresários e por interesse o do capital._Iasi (2013) cita uma passagem exemplar desse espírito de coesão, oferecida pelo então candidato à vice-presidência da República, Michel Temer, por ocasião de uma discussão com investidores estrangeiros na qual

[...] declarou que o país estava pronto para receber investimentos, uma vez que se trata de um país "internamente pacificado", no qual se "os movimentos sociais não estivessem pacificados, se os setores políticos não estivessem pacificados, [...] se aqueles mais pobres não estivessem pacificados [...] isto geraria uma insegurança. (Folha de S. Paulo, São Paulo, 27 ago.2010, caderno A, p.8 apud IASI, 2013, p. 287)".

Ainda quanto à formação docente, em 2011, no I Encontro Nacional do Plano Nacional de Professores da Educação Básica (Parfor), o então Ministro da Educação, Haddad, afirmava que "quem quiser ser professor vai ser financiado pelo poder público, mesmo que seja numa instituição particular". Com a mesma sutileza seu sucessor, 
Ministro, Mercadante, em 2013, em audiência na Comissão de Educação da Câmara dos Deputados, revelou que,

[...] preocupado com a baixa procura por cursos superiores de licenciatura em física, química, matemática e biologia, o Ministério da Educação (MEC) elabora um programa para, desde o ensino médio, atrair para essas áreas os estudantes que querem ser professores. A proposta, ainda em construção, prevê parceria com universidades e também a oferta de bolsas de auxílio. (CORREIO BRASILIENSE, 2013).

A política de incentivo aos professores por parte do Ministério tem ocorrido via bolsas, vinculadas a inúmeros programas. Ademais, na mesma ocasião, o então Ministro afirmou ainda ser "preciso estimular a vocação (sic!) de professor. Temos o problema salarial, de carreira, mas há também o problema de despertar o interesse pela educação desde cedo e valorizar quem tem esse interesse." (CORREIO BRASILIENSE, 2013).

Não foi outro o sentido do discurso da presidenta da República Dilma Roussef à Nação em primeiro de maio de 2013: "Somente a pressão de todos vai fazer os governos, as empresas, as igrejas, os sindicatos, em suma, toda a sociedade trabalhar ainda mais pela educação" (ROUSSEF, 2013). A articulação proposta por Roussef (2013) sintetiza o slogan "Brasil, pátria educadora!". Alheia talvez aos gravíssimos problemas que atingem a escola e o trabalho docente - e, por consequência, a população brasileira, mas muito diretamente os trabalhadores -, não se constrangeu ao afirmar que "Somente sua dedicação de mestre fará você, professor, superar as dificuldades que enfrenta".

O "poder baseado na dedicação" atribuído ao professor nas políticas públicas para a área educacional levou Triches (2010, p. 36) a criticar a posição política do Estado, não declarada, de que ele deveria tornar-se um superprofessor, cujas excessivas atribuições não encontram correspondência nem em sua formação, nem em suas condições de trabalho. A autora, ao analisar as atuais diretrizes curriculares para o curso de Licenciatura em Pedagogia (BRASIL, 2006a), articuladas às indicações de OM, afirma que quatro elementos compõem o superprofessor, implícitos no slogan "a profissão que pode mudar um país":

O primeiro diz respeito ao processo de reconversão ao qual se pretende submetê-lo, propondo-se que se abandone o professor tradicional e adira ao "novo" professor, isto é, multifuncional, polivalente, responsável, flexível, afeito as tecnologias, inclusivo, tolerante, aprendendo ao longo da vida e, acima de tudo, sem crítica as determinações de sua própria condição de professor. [...] O segundo elemento, articulado ao primeiro, refere-se ao alargamento do campo de atuação pela multiplicação de suas funções e pela ampliação das competências que dele se espera. $O$ terceiro relaciona-se à ampliação dos conteúdos da formação, resultando em um currículo inchado, restringindo-se o tempo e a qualidade da formação. Nesse caso, discussões teóricas verticalizadas tornam-se supérfluas. O quarto elemento vincula-se a uma imprecisão na definição do ser professor. (TRICHES, 2010, p.151).

Considera ainda que, "contraditoriamente, ao se constituir como superprofessor, ele é constituído como professor-instrumento [...]" cujo objetivo seria o de transformá-lo em colaborador para "a manutenção da hegemonia burguesa". (TRICHES, 2010, p. 36). Este 
tipo de conclamação coloca o professor como instrumento da política estatal e o estereotipa como um superprofessor, responsabilizando-o por questões além da sua função.

Conquanto análises como a acima tenham sido feitas, a posição do Ministério é a de que as várias licenciaturas deveriam ser reformadas, a exemplo da que ocorreu na Licenciatura em Pedagogia: "É indispensável, por conseguinte, a revisão dos currículos das licenciaturas plenas - como já se fez com o curso de Pedagogia - e a criação de licenciaturas abrangentes (licenciaturas por área)." (RUIZ; RAMOS;HINGEL, 2007, p. 19). A lógica da reforma proposta seria a da "formação de professores 'polivalentes', a princípio, em nível das universidades mantidas pelo Poder Público." (RUIZ; RAMOS;HINGEL, 2007, p. 21).

Evidencia-se que a pertinência das políticas do Governo Federal para a formação docente deve ser interrogada. Os números apresentados permitem perguntarmos pelo sentido da formação docente no Brasil. Claro está que tais políticas têm em vista o estreito preparo da "força de trabalho", esclarecendo-se, assim, o que Mészáros (2005, p. 45) assinalou acerca das instituições formais de educação: "Uma das funções principais da educação formal das nossas sociedades é produzir tanta conformidade ou 'consenso' quanto for capaz, a partir de dentro e por meio dos seus próprios limites institucionalizados e legalmente sancionados". Mas o mesmo autor chama a atenção para o fato de que essa é apenas uma parte de suas funções: "Se, entretanto, os elementos progressistas da educação formal forem bem-sucedidos em redefinir a sua tarefa num espírito orientado em direção à perspectiva de uma alternativa hegemônica à ordem existente, eles poderão dar uma contribuição vital para romper com a ordem do capital, não só no seu próprio e mais limitado domínio, como também na sociedade como um todo" (MÉSZÁROS, 2005, p. 59). Portanto, a escola pode ter papel importante rumo a uma "educação para além do capital".

\section{ALGUMAS CONSIDERAÇÕES FINAIS}

A análise da documentação permite afirmar que a preocupação, de $O M$, de organizações, do Estado e dos intelectuais envolvidos na construção desse ideário, marcado pela ambiguidade, pela dualidade e pela ubiquidade, é a de criar um consenso em que se torna imperativo tomar o professor como sujeito necessário e estratégico para amenizar os problemas sociais e humanizar a ordem capitalista. Neves e Martins (2010, p. 37) assinalam que tais ações e investimentos representam um artifício de "reeducação escolar e política" da sociedade que, tendo por objetivo

[...] reduzir os níveis de consciência política coletiva das várias frações da classe trabalhadora, impulsiona seus intelectuais coletivos a pautarem suas agendas políticas por demandas que, embora realizem mudanças parciais nas condições de trabalho e de vida das classes dominadas, mantêm praticamente inalteradas as relações de exploração e de expropriação concernentes às relações sociais capitalistas.

Essa abordagem da formação e do trabalho docente teve seu impulso no Brasil no início dos anos de 1990, entretanto, foi a partir da primeira gestão de Fernando Henrique Cardoso na presidência da República (1995-2002) que se desenvolveu um conjunto de ações tendo em vista a "reforma educacional" ". Para que essa reforma se consolidasse, era necessário reconverter o professor; torná-lo um sujeito que, diante de todos os problemas, fizesse a "diferença". Contudo, essa diretriz não se realizou plenamente, embora sua formulação em geral tenha obtido larga concordância. O excerto que segue é elucidativo: 
"O design e a implementação das reformas da educação geralmente encontram restrições políticas pelo caminho, dentre elas, por exemplo, a resistência dos sindicatos dos professores e de funcionários públicos em órgãos da educação [...]." (BANCO MUNDIAL, 2010c, p. 15).

O tema da reforma foi, portanto, retomado. Na Estrategia de Educación 2020 (BANCO MUNDIAL, 2011a) "aprendizagem para todos" é o grande norte e para alcançálo o Banco "canalizará os seus esforços para a educação em duas vias estratégicas: reformar os sistemas de educação no nível dos países e construir uma base de conhecimento de alta qualidade para reformas educacionais no nível global." (BANCO MUNDIAL, 2011b, p. 5) De sua ótica, o Brasil operou uma "revolução na gestão educacional", conseguiu "grandes avanços educacionais nos últimos 15 anos e elegeu como objetivo audacioso alcançar os níveis de qualidade da OCDE até 2021." (BANCO MUDIAL, 2011b, p. 13).

A reforma demandada, de fato, trata apenas dos novos passos a serem dados na mesma direção ${ }^{18}$. No que tange à formação docente, uma parte da cantilena é repetida: menos cursos teóricos, mais programas de treinamento, mais vídeos com aulas, mais exercícios práticos, mais técnicas de gerenciamento de classe, mais materiais didáticos, mais engajamento docente e mais observação de práticas exitosas.

A continuidade da agenda capitalista global em termos nacionais, encontrada no documento do Banco Mundial Atingindo uma educação de nível mundial no Brasil: próximos passos (BANCO MUNDIAL, 2010a, p. 6),compõe-se de quatro desafios centrais para a educação 2010-2020: "melhorar a qualidade dos professores, garantir o desenvolvimento infantil das crianças mais vulneráveis, construir um sistema de ensino médio de classe mundial e maximizar o impacto das políticas federais de educação básica". Para a agência, os mais de 5.500 sistemas de ensino fazem do Brasil um "laboratório de ação educacional" na medida em que oferece um vasto campo de observação de práticas educacionais exitosas que devem ser localizadas e difundidas, tendo em vista que "poucos outros países do mundo têm a mesma escala, alcance e criatividade de ação política que se encontra hoje no Brasill". Por essa razão, dever-se-ia aproveitar o laboratório "através de avaliações de impacto de programas inovadores e promoção de políticas e práticas com base em eficiência." (BANCO MUNDIAL, 2010a, p. 8). A suposta qualidade que emergiria desse laboratório serviria de base para a transformação da educação, tornando-a de nível mundial. Neste caldeirão, pululariam as boas práticas a serem pinçadas e reproduzidas no Brasil, e no mundo!

Desta forma, há um discurso hegemônico entre Organizações Multilaterais e Estado que demonstra "uma tendência crescente à homogeneização das políticas em nível mundial." (SHIROMA; CAMPOS; GARCIA, 2005, p. 2). Estamos frente, como assinalado, à "nova pedagogia da hegemonia" (NEVES et al., 2005, 2010) para a qual interessa a permanência das relações de exploração e maximização dos lucros, ou seja, para que ocorra a internalização da lógica do capital (MÉSZÁROS, 2005).

Para Fontes (2012, p. 30), essa espécie de formulação contou "com uma esquerda que, formada na luta de classes e ágil na retórica, abandonou seu campo original e se oferece como a melhor qualificada para essa conversão". Segundo Neves et al. (2005, 2010), é preciso usar a formação e o trabalho docente para colaborar com a permanência das relações de exploração e maximização dos lucros, para manter o capitalismo incontestado. 
A demanda oficial é falsa, dado que intrinsecamente irrealizável.A mudança do país - qualquer que seja - não está na esfera de atuação do professor, nem como criação nem como solução. Paradoxalmente, o apelo ao professor não significa sua valorização social, mas sua desqualificação nos planos discursivo e material. Compõe tal apelo a ideia de ausência - estaria ausente no professor mais vontade de ensinar; capacidade de refletir sobre sua prática; boa formação inicial; mobilização; investimento na formação continuada; implementar a política governamental... A lista das incapacidades do professor elencadas pelos reformadores é longa. Não raro, estão ausentes dessas preleções as condições materiais do trabalho e da existência do professor.

Seus detratores e a avaliação preconceituosa sobre os docentes e pretendentes ao magistério desconsideram que os professores são oriundos de escolas abandonadas pelo Estado, como eles, precisamente por serem altamente estratégicas para o capital. Nas palavras de Neves e Pronko (2008, p. 52) "a escola brasileira foi se direcionando também para a formação de subjetividades coletivas, com vistas à construção de um amplo consenso social em torno da concepção de mundo burguesa em tempos de novo imperialismo".

Se em oposição ao velho professor o novo precisa ser alimentado - polivalente, flexível, inclusivo, tolerante, inovador, tecnológico, responsabilizado pelo resultado de sua ação educativa e pela empregabilidade de seus alunos - é precisamente essa a contradição, objetiva e concreta, a ser explorada se quisermos consolidar a hegemonia do trabalho. Se podemos afirmar que, em última instância, pede-se ao professor que seja produtor de sua própria alienação, afirmamos também que esse pedido petulante possa ser respondido, posto que há um "fantasma a rondá-lo", expresso nas palavras de Fontes (2012, p. 30):

Os valores não desapareceram sob os grotões ou nas grandes cidades. É por existirem que a conversão é necessária. No entanto, esse é um jogo perigoso. $\mathrm{O}$ reservatório transbordante de capitais e de energias reconvertidas não pode assegurar essa forma de política hoje hegemônica. A crise ronda. Pode retomar formas truculentas, como a ascensão de uma velha direita na Europa; pode se defrontar com o recrudescimento das verdadeiras lutas de classes, agora dispostas a destruir esse dique.

O slogan"a profissão que pode mudar um país", como afirmamos, é ludibrioso e integra um discurso emblemático e ideológico. Os bordões elencados expressam o tratamento dado ao professor das instituições públicas, cujas incumbências, tais como produzir um país mais justo, democrático, forte economicamente, sem miséria, tolerante, carinhoso, entre outras, configuram um processo de superresponsabilização dos professores pelos problemas brasileiros. Despolitiza-se sua inserção social e se obscurece tanto a origem dos problemas econômicos quanto suas possíveis soluções, ambas implicadas organicamente na relação capital-trabalho.

Não imaginemos, entretanto, que somos todos indiferentes ao que sucede conosco, professores. Gramsci (1917) ilumina nosso caminho: "Sou militante, estou vivo, sinto nas consciências viris dos que estão comigo pulsar a atividade da cidade futura que estamos a construir". 


\section{REFERÊNCIAS}

BANCO MUNDIAL. Ceara: experiências na formação de professores. Departamento de Desenvolvimento Humano; Diretoria do Brasil. Novembro de 1999. Brasília, Brasil: BM, 1999.

BANCO MUNDIAL. Atingindo uma educação de nível mundial no Brasil: Próximos Passos. Sumário executivo. Brasília, Brasil: Banco Mundial, 2010a.

BANCO MUNDIAL.Achieving World Class Education in Brazil: The Next Agenda.Human Development Sector Management Unit and Latin America and the Caribbean Regional Office.December 21, 2010, 2010b. Disponível em: <http://portal.mec.gov.br/index.php?option=com_content\&view=article\&id=16156>. Acesso em: 28 jul 2013.

BANCO MUNDIAL. Nota de Conceitos sobre a Estratégia para o Setor da Educação 2020. Banco Mundial, 2010c. Disponível em:

$<$ http://siteresources.worldbank.org/EDUCATION/Resources/ESSU/ConceptNote_BR.pdf z. Acesso em: 20 mai 2013.

BANCO MUNDIAL. Estrategia de Educación 2020 del Banco Mundial. Versión preliminar delresumen.Versión Preliminar. Para comentariosúnicamente. Banco Mundial, 2011a. Disponível em: <http://siteresources.worldbank.org/ EDUCATION/Resources/ESSU/463292-1269917617150/69154241279137061297/ExecSummary_Spanish.pdf>. Acesso em: 9mai 2013.

BANCO MUNDIAL. Aprendizagem para Todos. Investir nos conhecimentos e competências das pessoas para promover o desenvolvimento. Estratégia 2020 para a Educação do Grupo Banco Mundial. Resumo executivo. Washington/DC; Banco Mundial, $2011 b$.

BRASIL. Lei de Diretrizes e Bases da Educação Nacional n. 9.394/96, de 20 de dezembro de 1996. Estabelece as diretrizes e bases da educação nacional. Brasília: MEC, 1996. Disponível em: <http://www.mec.gov.br/legis/pdf/LDB.pdf.>. Acesso em: 17 jul 2003.

BRASIL. Resolução CNE/CP n. 1, de 15 de maio de 2006. Institui Diretrizes Curriculares Nacionais para o Curso de Graduação em Pedagogia, licenciatura. Brasília: CNE, 2006a. Disponível em: <http://portal.mec.gov.br/cne/arquivos/pdf/rcp01_06.pdf〉. Acesso em: 12 abr 2013.

BRASIL. Decreto $N^{o} 5.800$, de 8 de junho de 2006.Dispõe sobre o Sistema Universidade Aberta do Brasil - UAB. Brasília: Planalto, 2006b. Disponível em:

<http://www.planalto.gov.br/ccivil_03/_ato2004-2006/2006/decreto/d5800.htm>. Acesso em: 08 ago 2013.

BRASIL. Programa de Apoio ao Plano de Reestruturação e Expansão das Universidades Federais (Reuni). Diretrizes Gerais. Agosto de 2007. Brasília: MEC, 2007. Disponível em: <http://portal.mec.gov.br/sesu/arquivos/pdf/diretrizesreuni.pdf>. Acesso em: 08 ago 2013.

BRASIL. SBPC discute formação de professores. Terça-feira, 15 de julho de 2008 - 14:54. Brasília: MEC, 2008. Disponível em: 
$<$ http://portal.mec.gov.br/index.php?option=com_content\&task=view\&id=10869\%20>. Acesso em: 08 ago 2013.

BRASIL. Decreton ${ }^{\circ}$ 6.755, de 29 de janeiro de 2009. Institui a Política Nacional de Formação de Profissionais do Magistério da Educação Básica, disciplina a atuação da Coordenação de Aperfeiçoamento de Pessoal de Nível Superior-CAPES no fomento a programas de formação inicial e continuada, e dá outras providências. 2009. Disponível em: <http://www.planalto.gov.br/ccivil_03/_ato2007-2010/2009/Decreto/D6755.htm>. Acesso em: 25 mai. 2012.

BRASIL. Plano Nacional de Formação dos Professores. Apresentação. Brasília: MEC, 2009b. Disponível em: <http://portal.mec.gov.br/index.php?option=com_ content $\&$ view $=$ article $\& i d=13583 \&$ Itemid=971> . Acesso em: 08 ago 2013.

BRASIL. Censo Escolar da Educação Básica 2011. Resumo Técnico. Brasília: INEP, 2012. Disponível em: <http://download.inep.gov.br/educacao_basica/censo_escolar/ resumos_tecnicos/resumo_tecnico_censo_educacao_basica_2012.pdf $>$. Acesso em: 08 ago 2013.

BRASIL. Sinopse do Censo Escolar da Educação Básica 2013. Brasília: INEP, $2013 f$. Disponível em: <http://portal.inep.gov.br/basica-censo-escolar-sinopse-sinopse>. Acesso em: 18 maio 2015.

BRASIL. Sinopse do Censo da Educação Superior 2013. Brasília: INEP, 2015. Disponível em: 〈http://portal.inep.gov.br/superior-censosuperior-sinopse>. Acesso em: 18 maio 2015.

BRASIL. Expansão da rede Federal de Educação Profissional, científica e tecnológica. Expansão. Brasília: MEC, 2013c. Disponível em:

$<$ http://redefederal.mec.gov.br/index.php?option=com_content $\&$ view $=$ article $\&$ id $=52 \&$ Ite mid=2>. Acesso em: 08 ago 2013.

BRASIL.PROINFANTIL Web. Programa de Formação Inicial para Professores em Exercício na Educação Infantil (PROINFANTIL). Apresentação. Brasília: MEC, 2013a. Disponível em: <http://proinfantil.mec.gov.br/apresentacao.htm>. Acesso em: 08 ago 2013.

BRASIL. Programa de Formação de Professores em Exercício. Secretaria de Educação à Distância. PROFORMAÇÃO. Apresentação. Brasília: MEC, 2013b. Disponível em: <http://proformacao.proinfo.mec.gov.br/apresentacao.asp>. Acesso em: 08 ago 2013.

BRASIL. Lei $n^{\circ}$ 12.796, de 4 de Abril de 2013. Altera a Lei ${ }^{\circ} 9.394$, de 20 de dezembro de 1996, que estabelece as diretrizes e bases da educação nacional, para dispor sobre a formação dos profissionais da educação e dar outras providências. Brasília: Congresso Nacional, 2013d. Disponível em: <http://www2.camara.leg.br/legin/fed/lei/2013/lei12796-4-abril-2013-775628-publicacaooriginal-139375-pl.html>. Acesso em: 8ago 2013.

BRASIL. Seja um professor. Venha construir um Brasil mais desenvolvido, mais justo, com oportunidade para todos. Website. Brasília: MEC, 2013e. Disponível em: <http://sejaumprofessor.mec.gov.br/index.php>. Acesso em: 5ago 2013. 
CORREIO BRASILIENSE. MEC vai lançar programa para incentivar formação de professores. Exatas. Publicação: 10/04/2013 16h27, 2013. Disponível em:

<http://www.correiobraziliense.com.br/app/noticia/eu-estudante/professor/2013/04/10/ professor_interna,359642/mec-vai-lancar-programa-para-incentivar-formacao-deprofessores.shtml>. Acesso em: 12 abr. 2013.

DELORS, Jacques. Educação: um tesouro a descobrir. 4. São Paulo: Cortez; MEC; UNESCO, 2000.

EVANGELISTA, Olinda (Org.). O que revelam os slogans na política educacional. Araraquara: Junqueira\&Marin Editores, 2014.

EVANGELISTA, Olinda. Políticas educacionais, privatização e formação do professor no Brasil. In: LIMA, Antonio B. de; VIRIATO, Edaguimar O. (Org.). Política educacional e qualificação docente. 1 ed. Cascavel/PR: Assoeste, 2001, p. 13-30.

EVANGELISTA, Olinda. Rede Kipus e reconversão docente na América Latina e Caribe. In: Quarto Seminário Nacional Estado e Políticas Sociais, 2009, Cascavel PR. Quarto Seminário Nacional Estado e Políticas Sociais. Cascavel PR: UNIOESTE, 2009.

GRAMSCI, Antonio. Os intelectuais e a organização da Cultura. 7. Rio de Janeiro: Civilização Brasileira, 1989.

HOUAISS. Instituto Antônio Houaiss. Dicionário de língua portuguesa. São Paulo: editora Objetivo, 2004. Disponível em: <http://200.241.192.6/cgibin/HouaissNeth.dll/creditos>. Acesso em:_5ago 2013.

IASI, Mauro. Democracia de cooptação e o apassivamento da classe trabalhadora. Diário da Classe. 19 março 2013. Disponível em:

<http://www.diariodaclasse.com.br/forum/topics/democracia-de-coopta-o-e-oapassivamento-da-classe-trabalhadora>. Acesso em: 10 abr 2013.

LEHER, Roberto. Educação Popular e luta de classes: um tema do século XXI. RJ: UFRJ, 2012. (mimeo).

LELLA, Cayetano de. Modelos y tendencias de la formación docente. In: I Seminário de perfil e estratégia de formação docente. Organização da OEI. Lima, Peru, setembro, 1999. Disponível em: <http://www.oei.es/cayetano.htm>. Acesso em:10 out 2013.

MARX, Karl. O Capital. Crítica da Economia Política. O Processo de Produção do Capital. Livro 1, Volume 1. 3 ed. Rio de janeiro: Civilização Brasileira, 2012.

MCKINSEY e Company. Como os Sistemas Escolares de Melhor Desempenho do Mundo Chegaram ao Topo. Confidencial, 10 de junho de 2008. Disponível em: <http://www.todospelaeducacao.org.br//arquivos/biblioteca/2755c21f-ddb8-45a4-ae85cf637b2d231b.pdf>. Acessoem: 5 ago 2013.

MÉSZÁROS, Istán. A educação para além do capital. São Paulo: Boitempo, 2005.

NEVES, L. M ${ }^{\mathrm{a}} \mathrm{W}$.; PRONKO, M. A. O mercado do conhecimento e o conhecimento para o mercado. Rio de Janeiro: EPSJV, 2008. 
NEVES, Lúcia M. W.. As reformas da educação escolar brasileira e a formação de um intelectual urbano de novo tipo. In: Anais da 27a Reunião Anual da ANPED, 2004, Caxambu: ANPEd, 2004. Disponível em: < http://www.anped.org.br/reunioes/27/gt05/t0510.pdf>. Acesso em 8ago 2013.

OEI. Declaración de Tarija.In: XIII Conferencia Iberoamericana de Educación, Tarija, Bolívia, 4 e 5 de setembro de 2003, 2003b. Disponível em: <http://www.oei.es/xiiicie.htm>. Acesso em: 20 abr 2010.

PORTAL PLANETA UNIVERSITÁRIO. Qualificação do Professor: parcerias podem ser opção para Programas de Formação Docente. Notícias do Campus. 09 Abril 2013, 2013. Disponível em: <http://www.planetauniversitario.com/index.php/notas-do-campusmainmenu-73/29837-qualificacao-do-professor-parcerias-podem-ser-opcao-paraprogramas-de-formacao-docente>. Acesso em: 12 abr. 2013.

ROUSSEF, Dilma. Pronunciamento à nação da Presidenta da República, Dilma Rousseff, em cadeia nacional de rádio e TV, sobre o Dia do Trabalho.Planalto. 01/05/2013 às 21h05. Brasília: Planalto, 2013. Disponível em: <http://www2.planalto.gov.br/imprensa/ discursos/pronunciamento-a-nacao-da-presidenta-da-republica-dilma-rousseff-em-cadeianacional-de-radio-e-tv-sobre-o-dia-do-trabalho-1>. Acesso em: 2 maio 2013.

RUIZ, Antonio Ibañez; RAMOS, Mozart Neves; HINGEL, Murílio. Escassez de professores no Ensino Médio: propostas estruturais e emergenciais. Relatório produzido pela Comissão Especial instituída para estudar medidas que visem a superar o déficit docente no Ensino Médio (CNE/CEB). Maio de 2007. Brasília: MEC; CNE; CEB, 2007. Disponível em: 〈http://portal.mec.gov.br/cne/arquivos/pdf/escassez1.pdf〉. Acesso em: 08 ago 2013.

SHIROMA, Eneida O; EVANGELISTA, Olinda. A colonização da utopia nos discursos sobre profissionalização docente. In: RevistaPerspectiva, Florianópolis: NUP; UFSC, v.22, n. 2, p.525-545, jul./dez., 2004.

SHIROMA, Eneida O.; EVANGELISTA, Olinda. Profissionalização como estratégia de gerenciamento de professores. In: Revista de Estudos Curriculares, Braga/PT, n.2, 2003.

TRICHES, Jocemara. Organizações multilaterais e curso de pedagogia: a construção de um consenso em torno da formação de professores. Dissertação (Mestrado em Educação) Florianópolis, SC: PPGE/UFSC, 2010.

UNESCO. Balance de los 20 años del Proyecto Principal de Educación para América Latina y el Caribe. In: VII Reunión Del Comité Regional Intergubernamental del PRELAC, Santiago de Chile, agosto de 2000.

UNESCO. Educación de qualidad para todos: um asunto do direito humano. Documento de discusión sobre políticas educativas. In: II Reuniónintergubernamentaldel PRELAC.

Santiago, Chile: UNESCO, 2007.

VAILLANT, Denise. Construcción de la profesión docente em América Latina. Tendencias, temas y debates. In: PREAL n. 31. 2004. Disponível em: <www.preal.org/GTD/index.php>. Acesso em: 10 fev 2014. 
VAILLANT, Denise. Reformas educacionais: o papel dos docentes. In: Revista PRELAC, n. 1, junho de 2005, p. 38-51. Disponível em: $<$ http://www.unesco.cl/medios/biblioteca/documentos/reformas_educacionais_e_papel_dos _docentes_denise_vaillant_revista_prelac_portugues_1.pdf>. Acessoem: 12 fev 2014.

\footnotetext{
${ }^{1}$ Texto originalmente publicado como capítulo em 2014 no livro $O$ que revelam os slogans na política educacional de organização da Profa. Dra. Olinda Evangelista e editado pela Junqueira\&Marin Editores nos formatos impresso e eletrônico/digital/e-book - www.junqueiraemarin.com.br. Para esse artigo os dados quantitativos foram atualizados.

${ }^{2}$ Professora Voluntária no Programa de Estudos Pós-graduados em Educação (PPGE). Centro de Ciências da Educação (CED), Universidade Federal de Santa Catarina (UFSC). Doutora em Educação. Bolsista Produtividade em Pesquisa do CNPq. Coordenadora do Grupo de Estudos sobre Política Educacional e Trabalho (Gepeto) - www.gepeto.ced.ufsc.br. E-mail: olindaevangelista35@ hotmail.com.
}

${ }^{3}$ Professora no Departamento de Estudos Especializados em Educação (EED). CED, UFSC. Doutoranda no PPGE, CED, UFSC. Bolsista Fumdes/SC. Pesquisadora do Grupo de Estudos sobre Política Educacional e Trabalho (Gepeto). E-mail: jtriches@yahoo.com.br.

${ }^{4}$ Por slogan se entende "expressão concisa, fácil de lembrar, utilizada em campanhas políticas, de publicidade, de propaganda, para lançar um produto, marca etc." (HOUAISS, 2004). Entretanto, a problemática é mais complexa que a definição do dicionário. Ramos cita Reboul assinalando que slogan evoca "A ideia de uma afirmação ou de uma promessa suficientemente vaga para permitir todas as manipulações e, por fim, a ideia de uma falta de objetividade, de uma tendência oculta." (Reboul apud RAMOS, 2012, p. 25). A síntese pretendida pelos slogans alude à impossibilidade de apreender seu sentido, dado que neles se inscrevem múltiplas interpretações, perdendo-se de vista sua hipotética objetividade: "são assistemáticos, populares e produzidos para serem repetidos de forma veemente ou tranquilizadora, mas não a serem "gravemente meditados"; correm o risco de se tornarem "portadores de um argumento pretensamente inquestionável e irrecusável [...]”. (RAMOS, 2012, p. 26). Shiroma (2002) agrega: slogans são "pretensamente óbvios e inofensivos, forjados numa complexa construção de hegemonia, que não é monolítica, mas reiteradamente apela a 'sofisticadas estratégias linguísticas'." Shiroma e Evangelista (2014, p. 12) argumentam que as insígniasburguesas edulcoram suas promessas como "pote no fim do arco-íris", "obliterando a impossibilidade de serem alcançadas no capitalismo. Procede como o canalha que, ciente da inexistência do pote, aproveita-se da credulidade do outro que o busca, desenhando-o segundo seus interesses particulares."

${ }^{5}$ No website do MEC Seja um professorconstam informações sobre como se tornar um professor, mercado de trabalho, depoimentos, serviços, vídeos, materiais aos professores e curiosidades. Disponível em: <http://sejaumprofessor.mec.gov.br/>. Acesso em: 20 maio 2013.

${ }^{6} \mathrm{O}$ termo responsabilização distingue-se do termo responsabilidade. Entre as definições presentes no Houaiss, Dicionário da Língua Portuguesa, adotamos as seguintes: responsabilização: imputar responsabilidade a, tornar ou considerar responsável; responsabilidade: caráter ou estado do que é responsável.

7Quando não se consegue o "consenso espontâneo" as mudanças são impostas por meio da "coerção estatal", pela força física ou legal (GRAMSCI, 1989).

${ }^{8}$ McKinsey\&Company, Inc. é uma empresa norte-americana de consultoria em gestão global que se concentra na resolução de questões que preocupam os gestores sêniores. É conselheira de empresas, governos e instituições de vários países.

${ }^{9}$ Evento realizado entre 15 e 17/08/11, na Fundação Carlos Chagas (FCC), em São Paulo. Teve por objetivo "aprofundar um projeto de pesquisa conjunto sobre o trabalho do professor [...]" entre a UNESCO e a Fundação. Disponível em: <http://www.unesco.org/new/pt/brasilia/about-this-office/singleview/news/ international_seminar_discusses_research_on_teaching_profession/>. Acesso em: 20 maio 2013. 


\begin{abstract}
${ }^{10}$ Lembra-se que, apesar da determinação legal da formação em nível superior, durante a primeira década do ano de 2000, o governo federal lançou alguns programas que tinham por finalidade a formação de professores ainda em nível médio e na modalidade de Educação a Distância $(\mathrm{EaD})$, como o Programa de Formação Inicial para Professores em Exercício na Educação Infantil (PROINFANTIL), iniciado em 2005 e oferecido para professores sem formação atuantes na educação infantil e o Programa de Formação de Professores em Exercício (PROFORMAÇÃO), destinado aos docentes em serviço nos anos iniciais do Ensino Fundamental e/ou EJA (BRASIL, 2013a; 2013b). Ambos estão em funcionamento.
\end{abstract}

${ }^{11}$ Os dados de 2013, disponíveis na Sinopse da Educação Básica, foram acrescentados neste artigo, visto que na ocasião de sua primeira publicação (EVANGELISTA, 2014) não haviam sido divulgados pelo INEP.

${ }^{12}$ Na Sinopse de 2013 não consta a informação se havia professores com Ensino Fundamental incompleto.

${ }^{13} \mathrm{O}$ MEC informa que esse número "inclui todos os docentes da educação básica, inclusive auxiliares de ensino na educação infantil, atendimento educacional especializado (AEE) e atendimento complementar. O mesmo docente matriculado em mais de um curso foi computado em cada um deles." (BRASIL, 2012, p. 38).

${ }^{14}$ É interessante demarcar que no relatório produzido para o MEC indicou-se como soluções emergenciais para a carência de professores para o Ensino Médio: contratação de profissionais liberais como docentes, aproveitamento emergencial de alunos de licenciatura, bolsas de estudos para alunos carentes em escolas da rede privada, incentivo ao retardamento das aposentadorias de professores, incentivo para professores aposentados retornarem às atividades docentes, contratação de professores estrangeiros em disciplinas determinadas e uso complementar de tele-salas. (RUIZ; RAMOS; HINGEL, 2007).

15،LIDE é uma organização de caráter privado, que reúne empresários em nove países e quatro continentes. O LIDE debate o fortalecimento da livre iniciativa do desenvolvimento econômico e social, assim como a defesa dos princípios éticos de governança corporativa no setor público e privado. Fundado no Brasil, em 2003, o LIDE é formado por líderes empresariais de corporações nacionais e internacionais, que promove a integração entre empresas, organizações e entidades privadas, por meio de programas de debates, fóruns e iniciativas de apoio à sustentabilidade, educação e responsabilidade social. O LIDE reúne lideranças que acreditam no fortalecimento da livre iniciativa no Brasil e no mundo." De seu Comitê diretivo participam, por exemplo, Celso Lafer e Roberto Klabin. Osmar Zogbi é presidente do LIDE Educação. No site, afirma-se que o LIDE "Contribui com a resolução de um dos problemas mais críticos do Brasil: a Educação. Em parceria com o Instituto Ayrton Senna (IAS), tem como meta eliminar o analfabetismo no País". Zogbi é "Empresário com 40 anos de experiência no Setor de Celulose e Papel, foi presidente da Ripasa e da Associação Brasileira de Celulose e Papel. Preside, atualmente, a EcoBrasil Florestas e a EAZ Participações." (LIDE. Comitê. Disponível em: 〈http://www.lidebr.com.br/comite.as〉. Acesso em: 5 maio 2013).

${ }^{16}$ A matéria encaminhada pela Assessoria de Comunicação Social do MEC informa que "O ministro da Educação, Aloizio Mercadante, sugeriu a empresários que firmem parcerias com o MEC para estimular iniciativas destinadas à formação de professores. Em palestra proferida na tarde de segunda-feira, 8, em São Paulo, durante debate promovido pelo Grupo de Líderes Empresariais (LIDE), o ministro destacou a importância da contribuição do empresariado no apoio à formação docente, que é, segundo Mercadante, chave no processo educacional. [...] O encontro reuniu mais de 300 empresários de diversos setores. Quanto à importância de o empresariado participar do debate educacional, Mercadante comemorou o fato de o tema ser foco de interesse crescente [...].” (PORTAL PLANETA UNIVERSITÁRIO, 2013).

${ }^{17} \mathrm{~A}$ introdução do neoliberalismo no Brasil ocorreu, como se sabe, no Governo Collor, no início dos anos de 1990. Em termos educacionais, porém, foi no Governo FHC que a reforma se consolidou.

${ }^{18}$ No documento Estrategia de Educación 2020 del Banco Mundial. Versión preliminar delresumén, o BM apresenta diretrizes para uma reforma. São dois os pressupostos: a educação é fundamental para o desenvolvimento de uma nação e a aprendizagem é para todos (o slogan anterior era "Educação para Todos"). Desses pressupostos decorreriam reformas respaldadas pelo BM tendo em vista fortalecer os sistemas educativos nos vários países, incrementar o uso adequado de recursos públicos, apoiar financiamentos para a educação, ajudar o desenvolvimento de uma base de conhecimentos com dados relativos às políticas que têm êxito e que não têm e formular novo conceito de "sistema de ensino" pela 
inclusão de instituições empresariais e outras formas de organização, assim como pessoas. (BM, 2011a, p. 3). Na Nota de Conceitos sobre a Estratégia para o Setor da Educação 2020 o BM reafirma seu slogan central: aprendizagem para todos segundo a necessidade e a capacidade de cada um. O alcance dessa proposta demanda, da ótica do Banco: 1) orientação do sistema para viabilizar aprendizagem para todos; 2) financiamento baseado em resultados; 3) enfoque multissetorial para o desenvolvimento educacional; 4) compromisso de fomentar a educação tendo em vista: a) investimento no crescimento a longo prazo e b) redução da pobreza, melhora da vida das pessoas. As prioridades elencadas são: vincular novamente a educação à agenda de desenvolvimento; apoiar maior acesso equitativo à educação; assegurar melhor aprendizagem e melhor aquisição de aptidões; apoiar investimentos para fortalecer os sistemas educacionais e abordagem sistêmica no trato da Educação. As duas últimas são novidades em relação às estratégias anteriores.

Recebido: $\quad$ jun/2015 $\quad$ Aprovado: jul/2015 